\title{
Sensory Modulation Impairments in Children with Williams Syndrome
}

\author{
Angela E. John and Carolyn B. Mervis \\ University of Louisville
}

\begin{abstract}
The ability to organize information detected by our senses ("sensory modulation") allows us to act or respond effectively to situations encountered, facilitating learning, social behavior, and day to day functioning. We hypothesized that children with Williams syndrome (WS) would demonstrate symptoms of poor sensory modulation and that these sensory modulation abnormalities contribute to the phenotype. Participants were 78 children with WS aged $4.00-10.95$ years. Based on parent ratings on the Short Sensory Profile [SSP; Dunn, 1999], most children were classified as having definite sensory modulation issues. Cluster analysis identified the presence of two clusters varying in level of sensory modulation impairment. Children in the high impairment group demonstrated poorer adaptive functioning, executive functioning, problems behaviors, and more difficult temperaments than children in the low impairment group.
\end{abstract}

\section{Keywords}

Williams syndrome; sensory modulation; intellectual disability; executive function; temperament; adaptive behavior; problem behaviors

\section{INTRODUCTION}

As people navigate the world around them they experience a myriad of sensations (e.g., touch, movement, sight, sound) from both their bodies and their surrounding environment. When a person efficiently processes sensory input, sensations from one or more sensory systems (e.g., auditory, tactile, vestibular) are detected and integrated allowing the body to regulate and manage sensory input from multiple modalities in a graded and adaptive manner. This process is referred to as sensory modulation [e.g., Dunn, 1997; Gal et al., 2007; Mulligan, 2002]. Sensory modulation allows an individual to single out key information from the sensations experienced, giving meaning to his or her environmental experiences. As such, sensory modulation is vital to day to day functioning, learning, and social behavior [Ayres, 1972; Dunn, 1997]. These are supported when sensory stimuli are not overwhelming and emotions are well regulated [Miller et al., 2004]. People have different thresholds for noticing and responding to sensations within their environment. Once sensations become overwhelming, the person is likely to respond negatively [e.g., Dunn, 2001; Miller et al., 2004].

Children with sensory modulation impairments often demonstrate difficult temperaments, problem behaviors, planning impairments, inattention, difficulty regulating arousal levels, and trouble establishing relationships [e.g., Ayres, 1972; Baranek et al., 2002; Kranowitz,

Address Correspondence to: Angela E. John, Dept. of Psychological and Brain Sciences, University of Louisville, Louisville, KY 40292. Telephone: 502-852-4638. Fax: 502-852-8271. aejohn11@gwise.louisville.edu. 
2005; Lane, 2008; Mangeot et al., 2001; Ornitz, 1971]. It has been argued that features of the behavioral phenotypes associated with a variety of developmental, psychiatric, and neurological conditions (e.g., autism spectrum disorders, fragile X syndrome, ADHD) are potentially secondary to effects of underlying sensory modulation impairments [e.g., Baranek et al., 2002; Dunn and Bennett, 2002; Mangeot et al., 2001; Ornitz, 1971; Ornitz, 1989; Tomchek and Dunn, 2007]. In the present study, we considered the sensory modulation abnormalities associated with Williams syndrome (WS) and their correlates.

WS is a neurodevelopmental disorder resulting from a hemideletion of $\sim 25$ genes on chromosome 7q11.23 [Osborne, 2006] with a prevalence of 1 in 7500 live births [Strømme et al., 2002]. WS is characterized by mild to moderate intellectual disability or learning difficulties, dysmorphic facial features, and heart disease, especially supravalvar aortic stenosis [Morris, 2006]. WS has drawn attention from researchers due to its unusual cognitive and personality profiles. The WS cognitive profile is characterized by relative strengths in verbal short-term memory and the structural and concrete components of language accompanied by severe weakness in visuospatial construction [Mervis and Morris, 2007; Mervis et al., 2000; Udwin and Yule, 1990].

The WS personality profile involves high levels of sociability, an over-eagerness to interact with others, sensitivity, and tenseness [Klein-Tasman and Mervis, 2003]. Children with WS also demonstrate maladaptive emotional and/or physical responses to environmental stimuli including abnormal sensitivity or reactivity to sound, distractibility, ritualism, and indiscriminant social behavior [Gillberg and Rasmussen, 1994; Leyfer et al., 2006; Mervis and Klein-Tasman, 2000; Pober and Dykens, 1996].

To date, relatively little is known about the presence of sensory modulation abnormalities in individuals with WS. Dilts and colleagues [1990] proposed that WS was associated with a distinct behavioral phenotype which included sensory integrative dysfunction, specifically hypersensitivity to sound and vestibular input. Other researchers have reported increased sensitivity to sound and unusual attraction to or fascination with certain sounds [Einfeld et al., 1997; Klein et al., 1990; Levitin et al., 2005; Leyfer et al., 2006; Pober and Dykens, 1996; Udwin and Yule, 1990]. Two studies of older toddlers and preschoolers with WS [Klein-Tasman et al., 2007; Lincoln et al., 2007] report information on interest in or unusual response to sensory aspects of toys/surroundings during a semi-structured, play based interaction. Klein-Tasman and colleagues [2007] found that $45 \%$ of their sample demonstrated an unusual interest in nonfunctional sensory aspects of toys or surroundings; Lincoln and colleagues [2007] reported that $15 \%$ of their sample demonstrated unusual sensory interests. While the results of these studies provide some evidence of sensory modulation abnormalities, until now researchers have not specifically examined sensory modulation across domains.

In the present study, we posed the following research questions:

1. Do children with WS demonstrate sensory modulation abnormalities? If so, which domains are most affected? While there is research demonstrating an increased sensitivity to sound there have been no studies focused on determining the extent to which sensory abnormalities are evident in children with WS and if so, if these abnormalities are present in multiple domains. We hypothesized that the majority of children with WS would demonstrate sensory modulation abnormalities and that these abnormalities would be apparent in multiple domains.

2. Are children with WS easily divided into sensory-based subgroups based on pattern or degree of sensory impairment? Based on our observations working with children with WS, there appeared to be a group of children with WS for whom sensory 
modulation impairments were far more apparent and for whom these impairments seemed to interfere with their ability to navigate the world around them. As such, we hypothesized that two or more sensory-based subgroups of children with WS existed.

3. Do these subgroups differ in terms of their performance on measures of executive functioning and temperament? Executive functioning has been argued to provide a higher-level influence over sensory inputs [e.g., Gazzaley and D'Esposito, 2007; Shallice et al., 1989]. In addition, behavioral differences (e.g., differences in temperament) between children have been theorized to affect children's reactions to sensory experiences [e.g., Dunn, 1997, 2001]. Accordingly, we hypothesized that children with WS who demonstrate more severe sensory impairments would also demonstrate poorer executive functioning and more difficult temperaments.

4. Do these subgroups differ in terms of adaptive functioning and problem behaviors? Sensory modulation impairments have been argued to affect children's day to day functioning negatively [e.g., Ayres, 1972; Dunn, 1997]. As such, we hypothesized that children with WS who have more severe sensory modulation impairments would also demonstrate poorer adaptive functioning and more problem behaviors.

\section{METHOD}

\section{Participants}

Participants were 78 children with genetically-confirmed classic-length WS deletions (34 boys, 44 girls) aged $4.00-10.95$ years $(M=6.53, S D=2.14)$. Nine additional children were excluded because of comorbid diagnoses on the autism spectrum. The children were consecutive participants within the $4-10$-year-old age range in an ongoing study of the development of individuals with WS. The racial/ethnic constitution of the sample was: 83.1\% Caucasian, 6.5\% Hispanic, 5.2\% Asian, 2.6\% African American, and 2.6\% Native American.

\section{Measures}

Short Sensory Profile [SSP; McIntosh et al., 1999]-The SSP is a 38-item parent report measure comprised of the items from the Sensory Profile [Dunn, 1999] that demonstrated the highest discriminative power of atypical sensory modulation. Items are scored along a 5-point Likert scale describing the frequency with which a child demonstrates various behaviors. Lower scores indicate more difficulty. The SSP yields raw scores and classification categories (i.e., typical performance, probably abnormal, definitely abnormal) for both a total score and seven scales: Tactile Sensitivity (response to touch experiences), Taste/Smell Sensitivity (response to taste and smell experiences), Movement Sensitivity (response to movement experiences), Underresponsiveness/Seeks Sensation (level of noticing sensory events), Auditory Filtering (ability to use and screen out sounds), Low Energy/Weak (ability to use muscles to move), and Visual/Auditory Sensitivity (response to sights and sounds).

\section{Kaufman Brief Intelligence Test-second edition [KBIT-2; Kaufman and}

Kaufman, 2004] - The KBIT-2 is an individually administered assessment of verbal and nonverbal intelligence which yields an overall IQ, Verbal standard score, and Nonverbal standard score $($ mean $=100 ; S D=15)$.

Peabody Picture Vocabulary Test-III [PPVT-III; Dunn and Dunn, 1997]—The PPVT-III is an individually administered assessment of concrete receptive vocabulary (mean $=100 ; S D=15$ ). 
Behavior Rating Inventory of Executive Functioning [BRIEF; Gioia et al., 2000]

-The BRIEF is an 86-item questionnaire for parents of 6 -18-year-olds regarding executive functioning behaviors in both home and school environments. The subscales that we hypothesized to be affected by sensory modulation were: Shift, Emotional Control, Initiate, Working Memory, Plan/Organize, and Monitor.

Children's Behavior Questionnaire [CBQ; Rothbart and Ahadi, 1994]—The Long Form of the CBQ is a 327-item parent questionnaire. Parents rate how typical a given behavior is of their child using a 7-point scale. We hypothesized that subscales loading onto two higher order factors (Negative Affectivity and Effortful Control) would likely be impacted by sensory modulation. The Negative Affectivity factor includes the Discomfort, Fear, Anger/Frustration, Sadness, Falling Reactivity and Soothability (reverse-coded) subscales. The Effortful Control factor includes the Inhibitory Control, Attentional Focusing, Low-Intensity Pleasure, and Perceptual Sensitivity (reverse-coded) subscales. Subscale scores were calculated by taking the mean of all items on the subscale excluding items omitted or marked as "not applicable."

Scales of Independent Behavior-Revised [SIB-R; Bruininks et al., 1996]—The SIB-R is an assessment of adaptive behavior which yields an overall standard score in addition to standard scores for four clusters: Motor Skills, Social Interaction and Communication Skills, Personal Living Skills, and Community Living Skills (mean = 100; $S D=15)$. The parent interview form was administered.

Conners' Parent Rating Scale - Revised [CPRS-R(L); Conners, 1997]—The CPRS-R(L) is an 80-item parent questionnaire used to assess problem behaviors in 3 - 17year-olds. The CPRS-R(L) yields seven factors and several summary indices (mean $=50$; $S D=10$ ). We hypothesized that the following scales would be impacted by sensory modulation: Oppositional, Anxious, Social Problems, Restless/Impulsive, DSM-IV Symptoms Subscales: Inattentive, and DSM-IV Symptoms Subscales: HyperactiveImpulsive.

\section{Procedure}

Parents completed several questionnaires including the SSP, BRIEF, CBQ, and CPRS-R(L) and an interview regarding adaptive functioning (SIB-R). Children completed a battery of cognitive and language assessments including assessments of intellectual abilities (KBIT-2) and receptive vocabulary (PPVT-III).

\section{RESULTS}

\section{Overall Performance on the Short Sensory Profile}

Descriptive statistics for chronological age (CA), SSP, KBIT-2, and PPVT-III are reported in Table I. SSP data for 7 participants were incomplete due to missing items or items reported by the caregiver to be "not applicable" due to ability level or lack of opportunity. Per the instructions for the SSP, raw scores for the scales including these missing items were not computed. Thus, 2 participants were excluded from the Tactile scale calculations, 2 from the Taste scale calculations, 2 from the Auditory scale calculations, and 1 from the Visual/ Auditory Sensitivity scale calculations. All 7 children were excluded from the total score calculations. Only 7 children (9.9\%) were classified as 'typical performance' based on their SSP total score. More than half the sample (56.3\%) was classified as definitely having overall sensory modulation issues and an additional $33.8 \%$ was classified as probably having overall sensory modulation issues. Children's classifications on each of the seven subscales are shown in Figure 1. More than half of the children were classified as demonstrating 
definite abnormalities on the Auditory Filtering (59\%), Low Energy/Weak (64.1\%), and Under-responsive/Seeks Sensations (62.8\%) scales.

\section{Clusters/Subgroups and their Sensory Features}

To determine the extent to which scores on the SSP subscales allowed for the identification of homogeneous subgroups in the overall sample, a series of analyses was computed using SPSS 16.0.1 [SPSS, 2007]. First, a two-stage cluster analysis approach (a two-step cluster analysis using agglomerative hierarchical clustering, confirmed using a K-means cluster analysis) was used to determine the number of clusters or homogeneous subgroups in our sample. We then used a discriminant analysis to assess the adequacy of our final clusters and evaluate the relative importance of the variables used to establish these clusters. Of the original 78 participants, 7 were excluded from the remaining analyses due to missing items. Because the SSP scales are composed of a different number of items yielding different total score ranges, we converted the raw scores for each scale to $z$-scores. The two-step cluster procedure was used with the Bayesian information criterion (BIC) as an objective stopping rule/algorithm, to determine the optimal number of groups/clusters. Using this approach a cluster solution of two had the lowest BIC value (381.13). The minimum BIC difference was 19 demonstrating very strong support for a two-cluster solution. (BIC differences of $>10$ are classified as "very strong" evidence; Raftery, 1995.)

The consistency of the two-step cluster solution was then examined using a K-means cluster analysis method specifying this two-cluster solution. Centroids for both clusters were initially randomly generated; each participant was then assigned to the profile with the nearest centroid. The centroids were then recalculated and each participant was reassigned to a new cluster if his or her previously assigned centroid was no longer the nearest one. This iterative process was continued until no more re-assignment was possible [Anderberg, 1973]. A two-group cluster solution was specified and supported in three iterations using this method and demonstrated $85.92 \%$ agreement between the case classifications of the two clustering algorithms.

A simultaneous discriminant analysis was conducted to assess the adequacy of the final cluster assignments generated using the K-means cluster analysis and to determine the extent to which the 7 predictors: (a) Tactile Sensitivity, (b) Taste/Smell Sensitivity, (c) Movement Sensitivity, (d) Under-responsive/Seeks sensation, (e) Auditory Filtering, (f) Low Energy/Weak, and (g) Visual Auditory scores predicted cluster membership. The overall Wilks' lambda was significant $\left(\lambda=.23, \chi^{2}(7, N=71)=97.04, p<.001\right)$ indicating that the overall predictors differentiated between the two sensory clusters. The within-group correlations between the predictors and the discriminant function as well as the standardized weights are presented in Table II. The Under-responsive/Seeks Sensation score and the Low Energy/Weak score demonstrated the strongest relations with the discriminant function; the Movement scale score demonstrated only a weak relation, and the remaining scale scores demonstrated moderate relations with the discriminant function.

The discriminant function correctly classified $98.6 \%$ of all cases (compared to the K-means cluster assignments), indicating a valid model in support of our cluster membership assignment. Table III presents the raw score means and standard deviations along with the mean z scores of the seven SSP subscales for the two SSP cluster types. (Note: lower scores are indicative of greater difficulty.) An $\alpha$-level of .007 was required for an individual test to be significant to ensure that a family wise significance level of .05 was maintained. As indicated in Table 3, the means on each of the SSP scales were lower for Cluster 1 than for Cluster 2. These differences were statistically significant $\left(\alpha_{\mathrm{fw}}=.007\right)$ for all of the scales except Movement Sensitivity $(p=.03)$. As such Cluster 1 was labeled the High Impairment group (Hi-Imp, $n=31$ ) and Cluster 2 was labeled the Low Impairment group (Lo-Imp, $n=$ 
40). This conceptualization is further supported by examination of SSP Total Raw Score as a function of cluster membership (Figure 2). The two clusters did not differ significantly on chronological age (CA; $p=.82)$, KBIT-2 Composite IQ $(p=.15)$, or PPVT-III standard score $(p=.23)$.

\section{Comparison of Sensory Impairment Clusters/Subgroups: Executive Functioning and Temperament}

To determine if the two clusters differed with respect to executive functioning and temperament, two Hotelling's $T^{2}$ or two-group between-subjects MANOVAs using Wilks' criterion were performed (one for each measure). The data met the necessary statistical assumptions to support the remaining analyses (e.g., normality, equality of variancecovariance matrices). Descriptive statistics for performance on the standardized assessments as a function of subgroup are presented in Table IV.

BRIEF data were available for the 37 children aged 6 - 10 years (15 Hi-Imp; 22 Lo-Imp). The composite dependent variate for the MANOVA using the BRIEF subscales differed significantly as a function of sensory cluster membership (Wilks' $\lambda, F[6,30]=4.29, p=$. $003, \eta^{2}=.46$ ). Univariate ANOVAs were conducted on each dependent measure separately to determine the locus of the statistically significant multivariate effect. As indicated in Table 4, sensory cluster membership differed significantly as a function of: Shift $(p<.001$, $\left.\eta^{2}=.34\right)$, Emotional Control $\left(p=.001, \eta^{2}=.27\right)$, Initiation $\left(p=.001, \eta^{2}=.28\right)$, Working Memory $\left(p=.002, \eta^{2}=.24\right)$, Plan/Organization $\left(p=.001, \eta^{2}=.26\right)$, and Monitor $(p=.006$, $\eta^{2}=.20$ ) with children in the Hi-Imp group scoring lower (worse) than children in the LoImp group on all subscales.

The second MANOVA was conducted on the data from the CBQ subscales included in the Negative Affectivity and Effortful Control factors to determine if there were differences between sensory cluster groups in temperament. Data were missing for one child, leaving 70 participants ( $31 \mathrm{Hi}$-Imp; $39 \mathrm{Lo}$-Imp). The composite dependent variate differed significantly between the two sensory impairment groups (Wilks' $\lambda, F[9,60]=3.02, p=.005, \eta^{2}=.31$ ). Univariate ANOVAs were conducted on each dependent measure separately to determine the locus of the statistically significant multivariate effect. As indicated in Table IV, sensory cluster membership differed significantly as a function of three scales associated with Negative Affectivity: Anger/Frustration $\left(p<.001, \eta^{2}=.17\right)$, Sadness $\left(p=.02, \eta^{2}=.08\right)$, and Falling Reactivity and Soothability $\left(p=.001, \eta^{2}=.15\right)$. In addition, sensory cluster membership differed significantly as a function of two scales associated with Effortful Control: Inhibitory Control $\left(p=.009, \eta^{2}=.10\right)$, and Attentional Focusing $\left(p=.004, \eta^{2}=\right.$. 11). Children in the Hi-Imp group demonstrated more Anger/Frustration and Sadness and less Falling Reactivity/Soothability, Inhibitory Control, and Attentional Focusing than did the children in the Lo-Imp group. Differences between sensory cluster membership did not reach significance for: Discomfort $\left(p=.76, \eta^{2}=.001\right)$, Fear $\left(p=.24, \eta^{2}=.02\right)$, Low Intensity Pleasure $\left(p=.12, \eta^{2}=.04\right)$, and Perceptual Sensitivity $\left(p=.16, \eta^{2}=.03\right)$.

\section{Comparison of Sensory Impairment Clusters/Subgroups: Adaptive Functioning and Presence of Problem Behaviors}

To determine if the two groups differed with respect to adaptive functioning and problem behaviors, two Hotelling's $T^{2}$ or two-group between-subjects MANOVAs using Wilks' criterion were performed (one for each measure). The data met the necessary statistical assumptions to support the remaining analyses (e.g., normality, equality of variancecovariance matrices). Descriptive statistics for performance on the standardized assessments as a function of sensory impairment group are presented in Table 4. 
The first MANOVA was conducted on the four SIB-R scales to determine if adaptive functioning differed as a function of sensory impairment cluster (High or Low). SIB-R data were missing for 5 children leaving a total of 66 participants (30 Hi-Imp group; 36 Lo-Imp). The composite dependent variate differed significantly as a function of sensory cluster membership (Wilks' $\lambda, F[4,61]=4.96, p<.001, \eta^{2}=.25$ ). Univariate ANOVAs were conducted on each dependent measure separately to determine the locus of the statistically significant multivariate effect. As shown in Table 4, the two sensory groups differed significantly on all scales: Motor Skills $\left(p=.001, \eta^{2}=.17\right)$, Social Interaction and Communication Skills $\left(p=.001, \eta^{2}=.16\right)$, Personal Living Skills $\left(p<.001, \eta^{2}=.28\right)$, and Community Living Skills $\left(p<.001, \eta^{2}=.20\right)$ with children in the Hi-Imp group scoring lower (worse) than children in the Lo-Imp group on each subscale.

Finally, we examined the data from the CPRS-R(L) scales for which we had expected to find differences as a function of sensory cluster to determine if there were differences between the two groups on problem behaviors. CPRS-R(L) data were missing for 7 children resulting in a sample of 64 children (28 Hi-Imp; 36 Lo-Imp). The composite dependent variate differed significantly between the two sensory clusters (Wilks' $\lambda, F[5,58]=3.85, p$ $=.004, \eta^{2}=.25$ ). Univariate ANOVAs were conducted on each dependent measure separately to determine the locus of the statistically significant multivariate effect. As indicated in Table IV, sensory cluster membership differed significantly as a function of: Oppositional $\left(p=.04, \eta^{2}=.07\right)$, Anxious $\left(p=.002, \eta^{2}=.15\right)$, Social Problems $\left(p=.001, \eta^{2}\right.$ $=.16)$, Restless-Impulsive $\left(p=.006, \eta^{2}=.12\right)$, and Inattentive $\left(p=.02, \eta^{2}=.09\right)$ with children in the Hi-Imp group demonstrating greater difficulties. Effects of sensory group did not reach significance for Hyperactivity $\left(p=.21, \eta^{2}=.03\right)$.

\section{DISCUSSION}

Our results confirmed our hypothesis that based on parent report most children with WS demonstrate abnormalities in sensory modulation, as only $10 \%$ of our sample fell in the typical range for sensory modulation. The most problematic areas of sensory modulation included the ability to use muscles to move (e.g., poor muscle tone and postural control), noticing sensory events (e.g., poor modulation, either under- or over- responsive), and the ability to use or screen out sounds (e.g., hypo-responsive or hyper-responsive to sounds) with more than half of the children classified in the definite abnormality range in each of these domains.

Although the present study was the first that specifically focused on examining sensory modulation by children with WS across multiple domains, support for sensory modulation abnormalities in individuals with WS can be found in the existing research examining the WS phenotype. Results of such studies have demonstrated hypotonia [e.g., Mervis and Morris, 2007; Morris, 2005] and unusual responses to sensory aspects of the environment by children with WS [Klein-Tasman et al., 2007; Lincoln et al., 2007] to be characteristic of the WS phenotype. In particular our finding that children with WS demonstrate auditory sensory modulation abnormalities is well supported by prior studies documenting hypersensitivity to sound and poor auditory filtering in individuals with WS [Einfeld et al., 1997; Levitin et al., 2005; Leyfer et al., 2006; Marler et al., 2005]. For example, Levitin and colleagues [2005] documented a hypersensitivity to loudness of sounds in $79.8 \%$ of their WS sample as measured by parent report. Furthermore, $90.6 \%$ of the parents reported that their child with WS demonstrated auditory aversions. Therefore, it is likely that sensory modulation abnormalities play a key role in the WS phenotypic profile. Even though the overall pattern of sensory modulation abnormalities appears consistent for children with WS, the present study identified two clusters of children with WS varying in terms of sensory symptom severity. Thus, some children with WS demonstrate only mild abnormalities while for others 
the impairment in sensory modulation is more severe, but the pattern of abnormalities is similar for the two groups.

Both physiological differences and behavioral characteristics have been argued to play key roles in the manifestation of sensory modulation difficulties [Dunn, 1997; 2001; Parham and Mailloux, 2005; Miller et al., 2001]. Building on earlier working models of sensory modulation by Royeen and Lane [1991] and Dunn [1997], Miller and colleagues [2001] proposed the Ecological Model of Sensory Modulation (EMSM). According to the EMSM, contextual external dimensions (culture, environment, relationships, tasks) interact with internal dimensions (sensation, emotion, attention) to create effective or impaired sensory modulation. Each external dimension interacts with each internal dimension. These interactions serve either to support or to challenge an individual's responses within specific situations.

Of particular interest in the context of the present study are the EMSM internal dimensions proposed to impact sensory modulation. Miller et al. [2001] hypothesize that difficulty with sensory modulation is driven by an inability to receive and manage the sensory information that comes into the nervous system from the outside world ("sensation") which in turn affects both the ability to control impulses and activity levels ("attention") and the ability to regulate affect and behavioral responses ("emotion"). Thus, impairments in sensory modulation occur when the child's internal dimensions cannot smoothly accommodate the external dimensions of his or her world. In line with the EMSM, we expected the children in our two sensory clusters to differ in both executive function (higher-order cognitive processes argued to control/manage lower level cognitive processes such as attention) ability and temperament (affect and behavioral regulation). Executive control has been argued to provide higher-level influence over sensory input by allowing the individual to selectively focus limited cognitive resources on features of the environment that are relevant and to ignore elements that are irrelevant, thereby providing more sophisticated control over interactions with the environment [e.g., Gazzaley and D'Esposito, 2007; Shallice et al., 1989]. Miller et al. [2001] further hypothesize that maladaptive behaviors and difficulty functioning within one's environment are likely to occur if there is an "imbalance between the supports and demands of the external dimensions and the adaptive capacities of the internal dimensions (p. 61)." In accordance with this hypothesis, we anticipated that the children in our two sensory clusters also would differ in terms of both adaptive functioning and problem behaviors.

\section{Executive Functioning and Temperament}

Children in the Hi-Imp group demonstrated poorer performance than children in the Lo-Imp group on all aspects of executive functioning measured (i.e., transitioning from one situation/activity to another, modulating emotional responses appropriately, beginning a task or activity, staying on task, anticipating future events/setting goals, and monitoring one's own behavior/performance). Executive functioning ability evidenced the strongest relation to sensory modulation impairments, accounting for $46 \%$ of the group-difference plus associated error variance. Few researchers have directly examined the relation between sensory modulation impairments and executive functioning abilities. However, several other developmental, psychiatric, and neurological conditions (e.g., autism, schizophrenia, fetal alcohol syndrome, fragile $\mathrm{X}$ syndrome, ADHD) associated with sensory modulation impairments also have been shown to be associated with impairments in executive functioning [Baranek et al., 2002; Dunn and Bennett, 2002; Jirikowic et al., 2008; Kern et al., 2006; Ross et al., 2007].

The executive system is a theorized cognitive system argued to control/manage other cognitive processes. Gillbert and Burgess [2008] argued that "executive functioning allows 
us to behave flexibly, rather than being slaves to our environment and always behaving in a stereotyped manner when particular events occur...this equips us with the ability to adapt to novel, or changing situations." As such, it is likely that deficits in executive functioning are a significant contributing factor to the sensory impairments observed in WS and therefore, it is not surprising that children in the Hi-Imp cluster had poorer executive functioning than children in the Lo-Imp cluster. This finding also provides further support for Miller et al.'s [2001] position that the ability to sustain performance, including controlling impulses and activity level, is an internal dimension affecting sensory modulation.

Examining temperament variables, children in the Hi-Imp group demonstrated more negativity (i.e., Anger/Frustration, Sadness, Falling Reactivity/Soothability) and less effortful control (i.e., Inhibitory Control, Attentional Focusing) than children in the Lo-Imp group. Temperament accounted for $31 \%$ of the between-group variance plus associated error variance. Other researchers have theorized a relation between sensory modulation impairments and temperament characteristics. Consistent with the EMSM, Miller and colleagues [2004] argued that a child's well-being is supported when sensory stimuli are not overwhelming and when emotions are well regulated. People have different thresholds for noticing and responding to sensations within their environment. Once sensations become overwhelming, children who have difficulty regulating their emotions will be more negatively affected than those who are better able to regulate their emotions [Dunn 2001; Miller et al., 2001, 2004].

\section{Adaptive Functioning and Problem Behaviors}

Adaptive functioning ability reflects the degree to which one can cope with the demands of everyday life independently and meet age-level expectations for personal independence and social responsibility [American Psychiatric Association, 2000]. Almost all children with WS evidence difficulties with adaptive behavior. However, children in the Hi-Imp group demonstrated significantly poorer adaptive functioning than children in the Lo-Imp group. Overall, adaptive functioning ability accounted for $25 \%$ of the group-difference plus associated error variance. Prior research examining other neurodevelopmental disorders, including fetal alcohol syndrome, autism spectrum disorders, and fragile $\mathrm{X}$ syndrome, has also documented relations between sensory modulation and adaptive functioning [Baranek et al., 2002; Rogers et al., 2003].

It has been theorized that the ability to receive and integrate sensory inputs efficiently facilitates optimal functioning in daily environments [e.g., Ayres, 1972; Dunn, 1997; Jirikowic et al., 2008; Miller et al., 2001]. Adaptive behavior is considered to be one of the results of effective sensory integration [Bundy et al., 2002; Kranowitz, 2005]. Based on this position, researchers have hypothesized that poor sensory modulation limits a child's participation in activities of daily living, work, and leisure activities [Baker et al., 2008; Schaaf and Miller, 2005]. The results of our study provide additional support for the link between sensory modulation abilities and adaptive functioning.

Finally, children in the Hi-Imp group demonstrated more problem behaviors (i.e., oppositional behavior, anxiety, restless/impulsive behavior, inattention, difficulty with peers) than did children in the Lo-Imp group. Overall problem behaviors accounted for $25 \%$ of the group-difference plus associated error variance. Our findings are consistent with prior research. Sensory modulation is thought to reflect the interaction between behavioral thresholds and the thresholds of the central nervous system (CNS). As theorized by the EMSM, maladaptive behaviors may be a result of sensory modulation difficulties [Miller et al., 2001]. Maladaptive behaviors such as negative mood, symptoms of anxiety, and inattention have been demonstrated to be related to sensory modulation abnormalities [BenSasson et al., 2007; Cermak and Daunhaur, 1997; Dunn and Bennett, 2002]. 


\section{Conclusions and Future Directions}

Sensory modulation is an important substrate for higher-level learning, adaptive behavior, and social functioning [Ayres, 1972; Dunn, 2009; Parham and Mailloux, 2005]. The results of the present study indicated that, based on parent report, most children with WS demonstrate abnormalities in sensory modulation. Two clusters of children were identified varying in severity of sensory modulation impairments. Children demonstrating high impairments in sensory modulation evidenced significantly poorer executive functioning and adaptive functioning, more problem behaviors, and more difficult temperaments (less effortful control and more negative affectivity) than did children with less difficulty with sensory modulation. More research examining the nature and impact of sensory modulation abnormalities on the behavioral phenotype associated with WS is needed. In particular, while the present results indicate that sensory modulation difficulties are a key component of the WS phenotype, the developmental progression of sensory modulation difficulties is unknown. For example, studies are needed to address the question of whether significant sensory modulation difficulties are evident in young children with WS and the question of whether the difficulties identified in the present study for children in the late preschool and primary school period resolve over time or continue into adulthood. This line of research is vital to fully evaluate the impact of sensory modulation difficulties on the day-to-day functioning of individuals with WS. Improving sensory modulation would likely facilitate the ability of children with WS to navigate the world around them. Occupational therapy, both in its traditional form and in the form of sensory integration therapy often is used to address sensory modulation difficulties both for children in general and specifically for children with WS. Both desensitization (exposure) approaches such as the Replays technique recently proposed by Levine and Ched [2007] and cognitive behavioral therapy [Graham, 2005] also may be helpful in facilitating children's adjustment to situations they find overwhelming due to sensory modulation difficulties. Systematic evaluation of the effectiveness of these therapies in alleviating the impact of sensory modulation difficulties as well as determination of the circumstances under which a particular type of intervention is most likely to be effective (e.g., the impact of factors such as a child's executive functioning abilities and affective state on the effectiveness of a particular type of intervention) is crucial.

\section{Acknowledgments}

This research was supported by grants R37 HD29957 from the National Institute of Child Health and Human Development and R01 NS35102 from the National Institute of Neurological Disorders and Stroke. We thank the children and their parents for their enthusiastic participation in our research.

\section{Biographies}

Angela E. John, M.A, is a doctoral candidate in the Department of Psychological and Brain Sciences at the University of Louisville. Her primary research focus is on the language, cognitive, social-emotional, and behavioral development of children with Williams syndrome, Down syndrome, and duplication of the Williams syndrome region.

Carolyn B. Mervis, Ph.D., is a Distinguished University Scholar and Professor of Psychological and Brain Sciences at the University of Louisville. Her primary research focus is on the language, cognitive, social-emotional, and behavioral development of children with Williams syndrome, duplication of the Williams syndrome region, and Down syndrome. She also conducts research on neuroimaging and genotype/phenotype correlations involving the Williams syndrome region. 


\section{REFERENCES}

American Psychiatric Association. Diagnostic and Statistical Manual of Mental Disorders, 4th and, Text Revision (DSM-IV-TR). Washington DC: American Psychiatric Association; 2000.

Anderberg, MR. Cluster Analysis for Applications. New York: Academic Press; 1973.

Ayres, AJ. Sensory Integration and the Child. Los Angeles: Western Psychological Services; 1972.

Baker AE, Lane A, Angley MT, Young RL. The relationship between sensory processing patterns and behavioural responsiveness in autistic disorder: A pilot study. J Autism Dev Disord. 2008; 38:867875. [PubMed: 17899349]

Baranek GT, Chin YH, Hess LM, Yankee JG, Hatton DD, Hooper SR. Sensory processing correlates of occupational performance in children with fragile $\mathrm{X}$ syndrome: Preliminary findings. Am J of Occupational Therapy. 2002; 56:538-546.

Ben-Sasson A, Cermak S, Orsmond G, Carter A, Fogg L. Can we differentiate sensory overresponsivity from anxiety symptoms in toddlers? Perspectives of occupational therapists and psychologists. Infant Mental Health. 2007; J28:536-558.

Bruininks, RH.; Woodcock, RW.; Weatherman, RF.; Hill, BK. Scales of Independent Behavior Revised. Itasca, IL: Riverside Publishing Company; 1996.

Bundy, AC.; Lane, SL.; Murray, EA. Sensory integration: Theory and practice. Philadelphia, PA: Davis; 2002.

Cermak S, Daunhaur LA. Sensory processing in the post-institutionalized child. Am J of Occupational Therapy. 1997; 51:500-507.

Conners, CK. Conners' Rating Scales - Revised. Toronto: Multi-Health Systems Inc.; 1997.

Dilts CV, Morris CA, Leonard CO. Hypothesis for development of a behavioral phenotype in Williams syndrome. Am J of Med Genet (Suppl). 1990; 6:126-131. [PubMed: 2118772]

Dunn, LM.; Dunn, LM. Peabody Picture Vocabulary Test-III. Circle Pines, MN: American Guidance Services; 1997.

Dunn W. The impact of sensory processing abilities on the daily lives of young children and their families: A conceptual model. Infants and Young Children. 1997; 9:23-35.

Dunn, W. Sensory Profile. New York: The Psychological Corporation; 1999.

Dunn W. The sensation of everyday life: Empirical, theoretical, and pragmatic considerations - The 2001 Eleanor Clarke Slagle Lecture. Am J of Occupational Therapy. 2001; 55:608-620.

Dunn, W. A "sensational" way to understand and serve children: Illustration of a sensory processing model. In: Apps, JN.; Newby, RF.; Roberts, LW., editors. Pediatric Neuropsychology Case Studies: From Exceptional to Commonplace. New York: Springer; 2009. p. 281-294.

Dunn W, Bennett D. Patterns of sensory processing in children with attention deficit hyperactivity disorder. Occupational Therapy J of Res. 2002; 22:4-15.

Einfeld S, Tonge B, Florio T. Behavioral and Emotional Disturbance in Individuals With Williams Syndrome. Am J of Ment Retardation. 1997; 102:45-53.

Gal, E.; Cermak, SA.; Ben-Sasson, A. Sensory processing disorders in children with autism: Nature, assessment, and intervention. In: Gabriels, R.; Hill, D., editors. Growing up with autism: Working with school-age children and adolescents. New York, NY: Guilford Press; 2007. p. 95-123.

Gazzaley, A.; D'Esposito, M. Unifying prefrontal cortex function: Executive control, neural networks, and top-down modulation. In: Miller, BL.; Cummings, JL., editors. The Human Frontal Lobes: Functions and Disorders. New York: Guilford Press; 2007. p. 187-206.

Gillberg C, Rasmussen P. Brief report: Four case histories and a literature review of Williams syndrome and autistic behavior. J of Autism and Dev Disord. 1994; 24:381-393. [PubMed: 8050990]

Gillbert SJ, Burgess PW. Executive function. Curr Biol. 2008; 18:111-114.

Gioia, GA.; Isquith, PK.; Guy, SC.; Kenworthy, L. Behavior Rating Inventory of Executive Function. Lutz, FL: Psychological Assessment Resources, Inc.; 2000.

Graham, P. Cognitive Behavior Therapy for Children and Families. Cambridge: Cambridge University Press; 2005. 
Jirikowic T, Olson H, Kartin D. Sensory processing, school performance, and adaptive behavior of young school-age children with Fetal alcohol spectrum disorders. Physical and Occupational Therapy In Pediatrics. 2008; 28:117-136. [PubMed: 18846892]

Kaufman, AS.; Kaufman, NL. Kaufman Brief Intelligence Test - Second Edition. Circle Pines, MN: American Guidance Services; 2004.

Kern J, Trivedi M, Garver C, Grannemann B, Andrews A, Savla J, Johnson D, Mehta J, Schroeder J. The pattern of sensory processing abnormalities in autism. Autism. 2006; 10:480-494. [PubMed: 16940314]

Klein-Tasman BP, Mervis CB. Distinctive Personality Characteristics of 8-, 9-, and 10-Year-Olds With Williams Syndrome. Dev Neuropsychol. 2003; 23:269-290. [PubMed: 12730028]

Klein-Tasman BP, Mervis CB, Lord C, Phillips KD. Socio-communicative deficits in young children with Williams syndrome: Performance on the Autism Diagnostic Observation Schedule. Child Neuropsychol. 2007; 13:444-467. [PubMed: 17805996]

Klein A, Armstrong B, Greer M, Brown F. Hyperacusis and Otitis Media in Individuals with Williams Syndrome. J of Speech and Hearing Disord. 1990; 55:339-344. [PubMed: 2329796]

Kranowitz, CS. The out-of-sync child: Recognizing and coping with sensory processing disorder. New York: The Berkley Publishing Group; 2005.

Lane, SJ. Sensory integration. In: Accardo, PJ., editor. Capute and Accardo's neurodevelopmental disabilities in infancy and childhood: Vol 1: Neurodevelopmental diagnosis and treatment (3rd ed). Baltimore, MD: Paul H Brookes Publishing; 2008. p. 673-690.

Levine, K.; Chedd, N. Replays: Using play to enhance emotional and behavioral development for children with autism spectrum disorders. London: Jessica Kingsley Publishers; 2007.

Levitin DJ, Cole K, Lincoln AJ, Bellugi U. Aversion, awareness, and attraction: Investigating claims of hyperacusis in the Williams syndrome phenotype. J of Child Psychol and Psychiatry. 2005; 46:514-523. [PubMed: 15845131]

Leyfer OT, Woodruff-Borden J, Klein-Tasman BP, Fricke JS, Mervis CB. Prevalence of psychiatric disorders in 4 to 16-year-olds with Williams syndrome. Am J of Med Genet (Neuropsychiatr Genet). 2006; 141:615-622.

Lincoln AJ, Searcy YM, Jones W, Lord C. Social interaction behaviors discriminate young children with autism and Williams syndrome. J Am Acad of Child and Adolesc Psychiatry. 2007; 46:323331. [PubMed: 17314718]

Mangeot SD, Miller LJ, McIntosh DN, McGrath-Clarke J, Simon J, Hagerman RJ, Goldson E. Sensory modulation dysfunction in children with attention-deficit-hyperactivity disorder. Dev Med and Child Neurol. 2001; 43:399-406. [PubMed: 11409829]

Marler J, Elfenbein J, Ryals B, Urban Z, Netzloff M. Sensorineural Hearing Loss in Children and Adults With Williams Syndrome. Am J of Med Genet. 2005; 138:318-327. [PubMed: 16222677]

McIntosh, DN.; Miller, LJ.; Shyu, V.; Dunn, W. Short sensory profile. New York: The Psychological Corporation; 1999.

Mervis CB, Klein-Tasman BP. Williams syndrome: Cognition, personality, and adaptive behavior. Mental Retardation and Dev Disabil Res Rev. 2000; 6:148-158.

Mervis, CB.; Morris, CA. Williams syndrome. In: Mazzocco, MMM.; Ross, JL., editors. Neurogenetic Developmental Disorders: Variation of Manifestation in Childhood. Cambridge: MIT Press; 2007. p. $199-262$.

Mervis CB, Robinson BF, Bertrand J, Morris CA, Klein-Tasman BP, Armstrong SC. The Williams syndrome cognitive profile. Brain and Cogn. 2000; 44:604-628.

Miller, LJ.; Reisman, JE.; McIntosh, DN.; Simon, J. An ecological model of sensory modulation: Performance of children with Fragile X syndrome, Autistic Disorder, Attention Deficit/ Hyperactivity Disorder, and Sensory Modulation Dysfunction. In: Roley, SS.; Blanche, EI.; Schaaf, RC., editors. Understanding the nature of sensory integration with diverse populations. San Antonio, TX: Therapy Skills Builder; 2001.

Miller, LJ.; Robinson, J.; Moulton, D. Sensory Modulation Dysfunction: Identification in Early Childhood. In: DelCarmen-Wiggins, R.; Carter, A., editors. Handbook of infant, toddler, and preschool mental health assessment. New York, NY: Oxford University Press; 2004. p. 247-270. 
Morris, CA. Williams syndrome. In: Cassidy, SB.; Allanson, JE., editors. Management of genetic syndromes. 2nd ed.. Hoboken, NJ: Wiley; 2005. p. 655-665.

Morris, CA. The dysmorphology, genetics, and natural history of Williams-Beuren syndrome. In: Morris, CA.; Lenhoff, HM.; Wang, PP., editors. Williams-Beuren syndrome: Research, evaluation and treatment. Baltimore: The Johns Hopkins University Press; 2006.

Mulligan, S. Advances in sensory integration research. In: Bundy, AC.; Lane, SL.; Murray, EA., editors. Sensory integration: Theory and practice. Philadelphia, PA: Davis; 2002.

Ornitz, EM. Childhood autism: A disorder of sensorimotor integration. In: Rutter, M., editor. Infantile autism: Concepts, characteristics, and treatment. London: Churchill Livingstone; 1971.

Ornitz, EM. Autism at the interface between sensory processing and information processing. In: Dawson, G., editor. Autism: Nature, diagnosis, and treatment. New York: Guilford; 1989.

Osborne, LR. The molecular basis of a multisystem disorder. In: Morris, CA.; Lenhoff, HM.; Wang, PP., editors. Williams-Beuren syndrome: Research, evaluation, and treatment. Baltimore, MD: Johns Hopkins University Press; 2006. p. 18-58.

Parham, LD.; Mailloux, Z. Sensory integration. In: Case-Smith, J.; Allen, AS.; Pratt, PN., editors. Occupational therapy for children. 5th ed.. St. Louis, MO: Mosby; 2005. p. 356-405.

Pober BR, Dykens EM. Williams syndrome: An overview of medical, cognitive, and behavioral features. Child and Adolesc Psychiatric Clinics of North Am. 1996; 5:929-943.

Raftery AE. Bayesian model selection in social research. Sociological Methodol. 1995; 25:111-163.

Rogers S, Hepburn S, Wehner E. Parent Reports of Sensory Symptoms in Toddlers with Autism and Those with Other Developmental Disorders. J of Autism and Dev Disord. 2003; 33:631-642. [PubMed: 14714932]

Ross L, Saint-Amour D, Leavitt V, Molholm S, Javitt D, Foxe J. Impaired multisensory processing in schizophrenia: Deficits in the visual enhancement of speech comprehension under noisy environmental conditions. Schizophrenia Res. 2007; 97:173-183.

Rothbart MK, Ahadi SA. Temperament and the development of personality. J of Abnormal Psychology. 1994; 103:55-66.

Schaaf RC, Miller LJ. Occupational Therapy using a Sensory Integrative Approach for Children with Developmental Disabilities. Mental Retardation and Dev Disabil Res Rev. 2005; 11:143-148.

Shallice T, Burgess PW, Schon F, Baxter DM. The origins of utilization behavior. Brain. 1989; 112:1689-1693.

SPSS. SPSS 16.0 for Windows. Chicago, IL: SPSS, Inc.; 2007.

Strømme P, Bjørnstad PG, Ramstad K. Prevalence estimation of Williams syndrome. J of Child Neuropsychol. 2002; 17:269-271.

Tomchek SD, Dunn W. Sensory processing in children with and without autism: A comparative study using the Short Sensory Profile. Am J of Occupational Therapy. 2007; 61:190-200.

Udwin O, Yule W. A cognitive and behavioral phenotype in Williams syndrome. J of Clin and Experim Neuropsychol. 1990; 13:232-244. 


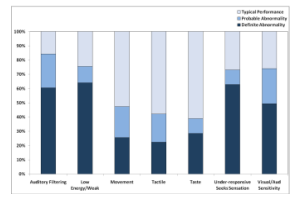

Figure 1.

Children's sensory modulation classifications as a function of SSP subscale. 


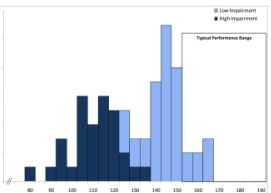

Figure 2.

Distribution of SSP total score for 714 -10-year-olds with WS as a function of sensory cluster. 
Table 1

Descriptive statistics for CA, SSP, cognitive, and language measures for entire sample.

\begin{tabular}{|c|c|c|c|c|}
\hline Measure & $N$ & Mean & SD & Range \\
\hline CA (in years) & 78 & 6.61 & 2.19 & $4.00-10.95$ \\
\hline \multicolumn{5}{|l|}{ SSP raw scores: } \\
\hline Tactile Sensitivity ${ }^{a}$ & 76 & 29.21 & 4.07 & $18-35$ \\
\hline Taste/Smell & 76 & 14.29 & 5.34 & $4-20$ \\
\hline \multicolumn{5}{|l|}{ Sensitivity $b$} \\
\hline Movement Sensitivity $c$ & 78 & 12.27 & 2.72 & $6-15$ \\
\hline Under- & 78 & 22.26 & 5.88 & $9-35$ \\
\hline \multicolumn{5}{|l|}{ responsive/Seeks } \\
\hline \multicolumn{5}{|l|}{ Sensation $^{a}$} \\
\hline Auditory Filtering $d$ & 76 & 18.17 & 4.08 & $10-27$ \\
\hline Low Energy/Weak ${ }^{d}$ & 78 & 19.82 & 6.51 & $7-30$ \\
\hline Visual Auditory $e$ & 77 & 16.13 & 3.51 & $8-25$ \\
\hline SSP Total Score & 71 & 132.14 & 20.36 & $83-168$ \\
\hline KBIT-2 IQ Composite & 71 & 76.76 & 15.40 & $40-111$ \\
\hline PPVT-III standard score & 62 & 81.74 & 16.68 & $40-109$ \\
\hline $\begin{array}{l}\text { SIB-R Broad Independence } \\
\text { standard score }\end{array}$ & 70 & 53.21 & 19.34 & $0-93$ \\
\hline
\end{tabular}

Note: $\mathrm{CA}=$ chronological age, $\mathrm{SSP}=$ Short Sensory Profile

$a_{\text {out of } 35 \text {; }}$

$b$ out of 20 ;

$c$ out of 15 ;

$d$ out of 30 ;

$e_{\text {out of } 25}$ 
Table 2

Standardized coefficients and correlations of predictor variables of the discriminant function.

\begin{tabular}{llll}
\hline Predictors & Wilks' $\lambda$ & $\begin{array}{l}\text { Correlation } \\
\text { Coefficients }\end{array}$ & Standardized Coefficients \\
\hline Under-responsive/Seeks & .63 & .41 & .67 \\
Sensation & & & \\
Low Energy/Weak & .63 & .41 & .78 \\
Visual Auditory & .71 & .35 & .41 \\
Taste/Smell Sensitivity & .72 & .34 & .62 \\
Auditory Filtering & .74 & .32 & .14 \\
Tactile Sensitivity & .75 & .31 & -.08 \\
Movement Sensitivity & .93 & .15 & .19 \\
\hline
\end{tabular}


Table 3

Mean raw score and standard deviations and mean z-scores for SSP Subscales for each cluster

\begin{tabular}{|c|c|c|c|c|}
\hline Type & $n$ & $M$ & $S D$ & $Z_{M}$ \\
\hline High Impairment Cluster & 31 & & & \\
\hline Tactile Sensitivity & & 26.94 & 4.40 & -.56 \\
\hline Taste/Smell Sensitivity & & 10.94 & 5.21 & -.59 \\
\hline Movement Sensitivity & & 11.45 & 2.91 & -.29 \\
\hline $\begin{array}{l}\text { Underresponsive/Seeks } \\
\text { Sensation }\end{array}$ & & 18.32 & 4.10 & -.68 \\
\hline Auditory Filtering & & 15.90 & 3.05 & -.58 \\
\hline Low Energy/Weak & & 15.10 & 5.40 & -.68 \\
\hline Visual/Auditory Sensitivity & & 14.00 & 2.61 & -.61 \\
\hline Low Impairment Cluster & 40 & & & \\
\hline Tactile Sensitivity & & 30.98 & 2.68 & .44 \\
\hline Taste/Smell Sensitivity & & 16.72 & 4.29 & .78 \\
\hline Movement Sensitivity & & 12.90 & 2.57 & .23 \\
\hline $\begin{array}{l}\text { Underresponsive/Seeks } \\
\text { Sensation }\end{array}$ & & 25.65 & 5.32 & .53 \\
\hline Auditory Filtering & & 20.12 & 3.92 & .45 \\
\hline Low Energy/Weak & & 22.98 & 5.03 & .53 \\
\hline Visual/Auditory Sensitivity & & 17.90 & 3.35 & .47 \\
\hline
\end{tabular}


Table 4

Univariate analyses of variance for adaptive functioning, executive functioning, problem behaviors, and temperament as a function of Sensory cluster membership

\begin{tabular}{|c|c|c|c|c|}
\hline & Univariate & & & \\
\hline Measure & Subscale & High $\operatorname{Imp} M(S D)$ & $\begin{array}{l}\text { Low Imp } \\
M(S D)\end{array}$ & $F$-value \\
\hline \multirow[t]{6}{*}{ BRIEF } & Shift & 70.13(9.15) & $55.32(11.35)$ & $17.67^{* * *}$ \\
\hline & Emotional Control & $66.13(9.76)$ & $54.77(9.79)$ & $12.04^{* *}$ \\
\hline & Initiation & $68.60(7.49)$ & $58.00(9.15)$ & $13.79^{* *}$ \\
\hline & Working Memory & $74.07(6.22)$ & $66.55(7.19)$ & $10.86^{* *}$ \\
\hline & Plan/Organize & $74.40(8.03)$ & 63.41(10.35) & $11.95^{* *}$ \\
\hline & Monitor & $72.47(6.57)$ & $65.05(8.18)$ & $8.56^{* *}$ \\
\hline \multirow[t]{9}{*}{ CBQ } & Discomfort & $4.55(0.93)$ & $4.48(0.91)$ & 0.10 \\
\hline & Fear & $4.09(0.78)$ & $3.84(0.97)$ & 1.39 \\
\hline & Anger/Frustration & $4.83(0.79)$ & $4.20(0.65)$ & $13.54^{* * *}$ \\
\hline & Sadness & $4.44(0.66)$ & $4.04(0.68)$ & $6.07^{*}$ \\
\hline & $\begin{array}{l}\text { Falling Reactivity and } \\
\text { Soothability }\end{array}$ & $4.14(0.92)$ & $4.80(0.71)$ & $11.73^{* *}$ \\
\hline & Inhibitory Control & $3.17(0.99)$ & $3.80(0.97)$ & $7.17^{* *}$ \\
\hline & Attentional Focusing & $2.67(0.68)$ & $3.19(0.78)$ & $8.67^{* *}$ \\
\hline & Low-Intensity Pleasure & $5.54(0.56)$ & $5.75(0.55)$ & 2.46 \\
\hline & Perceptual Sensitivity & $4.76(0.97)$ & $4.42(0.96)$ & 2.07 \\
\hline \multirow[t]{4}{*}{ SIB-R } & Motor & $51.63(16.11)$ & $63.86(15.36)$ & $13.01^{* *}$ \\
\hline & Social Interact/Comm & 61.87(18.76) & $73.89(17.58)$ & $11.94^{* *}$ \\
\hline & Personal Living & $45.55(16.78)$ & $64.47(17.27)$ & $24.51^{* * * *}$ \\
\hline & Community Living & $48.06(18.88)$ & $62.56(16.78)$ & $15.87^{* * *}$ \\
\hline \multirow[t]{6}{*}{ CPRS-R(L) } & Oppositional & $54.61(9.62)$ & $50.22(7.06)$ & $4.43^{*}$ \\
\hline & Anxious $^{a}$ & $54.14(11.12)$ & $46.72(7.11)$ & $10.53^{* *}$ \\
\hline & Social Problems & $70.32(15.85)$ & $57.44(13.91)$ & $11.95^{* *}$ \\
\hline & Restless/Impulsive & $73.89(12.76)$ & 63.97(14.49) & $8.18^{* *}$ \\
\hline & DSM Inattentive & 73.61(11.66) & $66.47(11.61)$ & $5.93^{*}$ \\
\hline & $\begin{array}{l}\text { DSM Hyperactive- } \\
\text { Impulsive }\end{array}$ & 66.93(10.92) & $62.67(14.88)$ & 1.61 \\
\hline \multicolumn{5}{|l|}{$* x<.05$} \\
\hline \multicolumn{5}{|l|}{$* * * 0.01$} \\
\hline \multicolumn{5}{|l|}{$* * * \quad p<.001$} \\
\hline
\end{tabular}

